\title{
PROJETO “E-WASTE - LIXO ELETRÔNICO” DO SENAI/SC EM SÃO MIGUEL DO OESTE
}

\author{
E-WASTE PROJECT OF SENAI/SC IN SÃO MIGUEL DO OESTE
}

\author{
Andrei Finco \\ e-mail: andreifinco@bol.com.br
}

\begin{abstract}
Gianfranco Brasil
Serviço Nacional de Aprendizagem Industrial (SENAI/SC), e-mail: brasil@sc.senai.br
\end{abstract}

\begin{abstract}
Resumo: Este case descreve algumas ações relacionadas ao resíduo eletrônico que foram desenvolvidas pelo Serviço Nacional de Aprendizagem Industrial (SENAI/SC) em São Miguel do Oeste a partir do projeto "E-waste - Lixo Eletrônico". Apresenta considerações acerca do que é lixo eletrônico, de quais metais pesados existem nos equipamentos eletrônicos, de quais metais estão presentes no computador e que materiais estão contidos em monitores cathode ray tube (CRT) e notebooks. Também são elaboradas elucidações a respeito da política ambiental adotada pelo SENAI nos últimos anos, da legislação do lixo eletrônico no Brasil e em alguns países do mundo e de como se desenvolveu o projeto "E-waste - Lixo Eletrônico" e sua campanha na cidade de São Miguel do Oeste.
\end{abstract}

Palavras-chave: Lixo Eletrônico. Consciência Ecológica.

Abstract: This case study describes some actions related to electronic waste that were developed by Serviço Nacional de Aprendizagem Industrial/SC (SENAI/SC) in São Miguel do Oeste - starting from the project "E-waste - Lixo Eletrônico". The case study presents considerations about what is electronic waste, which heavy metals exist in electronic equipment, which metals are present in the computer and which materials are contained in cathode ray tube (CRT) monitors and notebooks. Clarifications regarding the environmental policy adopted by SENAI in recent years, the law of e-waste in Brazil and some countries in the world are also described together with how the project "E-waste - Lixo Eletrônico" and his campaign was developed in the city of São Miguel do Oeste.

KeyWords: Electronic waste. Ecological awareness. 


\section{INTRODUÇÃO}

A atuação do Serviço Nacional de Aprendizagem Industrial (SENAI) em âmbito nacional e a sua condição de organização ligada ao setor industrial favorecem o desenvolvimento de trabalhos na busca de alternativas para amenizar os impactos ambientais provocados pelas indústrias, propiciando auxiliar as lideranças empresariais dos mais diversos setores industriais a gerenciarem seus empreendimentos de forma sustentável, otimizando o uso de recursos naturais.

Para o Serviço Nacional de Aprendizagem Industrial (1992, p.3):

a questão ambiental constitui-se em parâmetro portador de futuro e de competitividade para a indústria, já que, qualquer que seja o cenário, haverá uma crescente demanda por tecnologias de produção mais limpa e uma necessidade de adequação aos mecanismos reguladores de barreiras técnicas e comerciais, aos direitos do consumidor e ao exercício da cidadania que contemplam a preocupação com o meio ambiente.

A condição acima enfatiza claramente a preocupação que a instituição tem com o meio ambiente. Verifica-se que o SENAI vê as questões ambientais como um fator de competitividade para a indústria, pelo fato de que esta necessita adequar-se a um modelo de produção mais sustentável para manter-se no mercado.

Observa-se que os consumidores, cada vez mais, estão exigindo das indústrias ações sustentáveis e produtos que sejam processados de maneira eficiente. Deste modo, o SENAI observa uma crescente necessidade de se produzir tecnologias limpas que não agridam o meio ambiente e de uma reestruturação de todo o padrão de produção que vem sendo praticado pelas indústrias ao longo das últimas décadas (SERVIÇO NACIONAL DE APRENDIZAGEM INDUSTRIAL, 1992).

Nesse contexto, a instituição, como forma de diminuir os impactos causados ao meio ambiente, criou o Programa SENAI da Qualidade Ambiental - PSQA, desenvolvido em abrangência nacional. Esse programa teve como objetivo auxiliar as indústrias por meio de conhecimento e tecnologia para que houvesse uma reestruturação no setor de produção e para que, desse modo, os empresários conseguissem conciliar o crescimento de seus empreendimentos com o desenvolvimento social e ambiental da sociedade. Este programa, apesar de já encerrado foi de grande importância para as novas iniciativas implementadas pelo SENAI durante a sua história (SERVIÇO NACIONAL DE APRENDIZAGEM INDUSTRIAL, 1992).

No estado de Santa Catarina o SENAI também tem atuado de forma destacada em relação à gestão ambiental: 
através das consultorias ambientais, o SENAI/SC tem disseminado o entendimento sobre desenvolvimento sustentável entre as indústrias catarinenses, que consiste no desenvolvimento econômico, social e ambiental. Em 2009, o número de horas prestadas pelos consultores do SENAI neste tema totalizou quase duas mil e duzentas horas. Além disso, empresas obtiveram certificações ambientais com o apoio do SENAI/SC (SERVIÇO NACIONAL DE APRENDIZAGEM INDUSTRIAL, 2010a, p. 23).

O SENAI, através de seu Modelo de Excelência em Gestão (MEG) atua de forma comprometida com os fundamentos do desenvolvimento sustentável. Nesse sentido, estimula seus alunos a desenvolver projetos com foco ambiental, fazendo com que os mesmos tenham presente a importância de se preservar o meio ambiente e utilizar de forma racional os recursos naturais. Além disso, a instituição comemora todo o ano a Semana do Meio Ambiente onde realiza atividades diversas como oficinas de reciclagem, plantação de árvores, para que assim os alunos entendam a necessidade de se trabalhar tecnologia e preservação conservação ambiental concomitantemente (SERVIÇO NACIONAL DE APRENDIZAGEM INDUSTRIAL, 2010b).

O modelo de excelência em gestão, adotado pelo SENAI/SC, possui um critério denominado sociedade que fundamenta a responsabilidade socioambiental da instituição. Assim, esse critério engloba dois itens: a responsabilidade socioambiental o desenvolvimento social. Em relação à responsabilidade socioambiental, a mesma contém requisitos que têm por finalidade orientar a instituição com vistas à minimização de quaisquer impactos negativos que seus processos, produtos e instalações possam representar para a comunidade e também para a conservação de recursos naturais e a preservação da biodiversidade, dos ecossistemas. Vale ressaltar que tais elementos devem ser levados em consideração durante todo o ciclo de vida do produto (FUNDAÇÃO NACIONAL DA QUALIDADE, 2008).

[...]empresa deve considerar em sua gestão, além dos impactos do uso e descarte de seus produtos, também os aspectos relativos ao impacto provocado pelo descarte das embalagens de seus produtos. Uma prática proativa nesse sentido, usada por organizações de Classe Mundial, consiste no estabelecimento de "listas negras" com a indicação de materiais que não poderão ser usados em seus projetos (FUNDAÇÃO NACIONAL DA QUALIDADE, 2008, p. 9 )

Paralelamente a isso, o SENAI/SC também promove trimestralmente encontros com especialistas ambientais na área da indústria para que os mesmos possam contribuir com suas sugestões em relação a temas como tratamento de resíduos e efluentes e gestão ambiental (SERVIÇO NACIONAL DE APRENDIZAGEM INDUSTRIAL, 2010b).

Outra iniciativa da instituição é o Projeto Multi-Estadual de Eficiência Energética que consiste em uma parceria entre o SENAI dos estados de Santa Catarina, Rio Grande do Sul e Paraná, para estimular as indústrias de seus estados a aprimorar seus processos produtivos, diminuindo a poluição ambiental (SERVIÇO NACIONAL DE APRENDIZAGEM INDUSTRIAL, 2010b). 
Além disso, o SENAI/SC promove ações relacionadas a proteção ambiental entre seus colaboradores, alunos, fornecedores e sociedade. Desde o ano de 2006 acontece a chamada Semana do Meio Ambiente de 02 a 06 de junho. Na oportunidade os participantes desenvolvem uma série de atividades relacionadas à natureza (SERVIÇO NACIONAL DE APRENDIZAGEM INDUSTRIAL, 2010b).

Levando em consideração a responsabilidade socioambiental da instituição na sua gestão tanto em âmbito nacional quanto estadual, o SENAI - Departamento Regional de Santa Catarina, através da unidade de São Miguel do Oeste observou a necessidade de realizar ações para contribuir com a preservação do meio ambiente e o desenvolvimento de uma consciência ambiental entre seus colaboradores, alunos e a comunidade. A instituição verificou a importância de se dar um destino correto ao lixo eletrônico e de sensibilizar a sociedade no que tange a preocupação com os destinos do mundo em relação ao meio ambiente.

Para tanto, o SENAI/SC em São Miguel do Oeste decidiu trabalhar com uma grande problemática relacionada à poluição do planeta: o lixo eletrônico. Partindo da necessidade de se dar um destino correto a esse tipo de lixo produzido na unidade criouse um projeto ação intitulado "E-waste - Lixo Eletrônico".

Este projeto teve o objetivo de analisar o resíduo tecnológico encontrado na instituição, dando um destino adequado para o mesmo. Através dele buscou-se implantar formas mais eficazes para a gestão dos processos relacionados aos resíduos eletrônicos encontrados na unidade: recolhimento, separação, armazenamento e destinação.

A partir do projeto foi realizada uma campanha para o recolhimento desses equipamentos na cidade de São Miguel do Oeste. Esse evento serviu como modelo para a realização de outras campanhas nas demais cidades que fazem parte da Associação dos Municípios do Extremo Oeste de Santa Catarina (AMEOSC), fazendo com que o projeto tenha abrangência regional.

\section{LIXO ELETRÔNICO}

O lixo eletrônico é um resíduo que está presente na sociedade contemporânea e que pode causar inúmeros danos ao ser humano. A quantidade desse material vem aumentando acentuadamente e, paralelamente a esse aumento, houve uma crescente poluição decorrente da incorreta destinação desses resíduos.

Conforme Fonseca (2009, p. 70):

lixo eletrônico é a denominação genérica para todo tipo de descarte de equipamento eletro-eletrônico. Com o aumento contínuo na produção e consumo de eletrônicos, a quantidade desse tipo de lixo gerado a cada ano torna-se um problema cada vez maior. O lixo eletrônico não pode ser descartado junto com o lixo comum: o grande número de elementos tóxicos pode contaminar o meio ambiente. 
Os equipamentos eletrônicos possuem em seus componentes inúmeras substâncias nocivas à saúde humana e ao meio ambiente tais como: chumbo, mercúrio, cádmio, berílio. $\mathrm{O}$ contato com esses elementos pode trazer complicações levando o indivíduo até mesmo a morte. Se esses materiais forem dispersos no meio ambiente também podem poluir o solo, o lençol freático e o ar.

No quadro 1 estão relacionados os principais metais pesados existentes nos produtos eletrônicos e industriais, onde se encontram e as complicações que os mesmos causam ao ser humano:

\begin{tabular}{|c|c|c|}
\hline Metais & De onde vem & Efeitos \\
\hline Arsênio & $\begin{array}{l}\text { Metalurgia, manufatura de } \\
\text { vidros e fundição, celular. }\end{array}$ & $\begin{array}{l}\text { Câncer (seios paranasais), } \\
\text { doenças de pele, prejudica o } \\
\text { sistema nervoso. }\end{array}$ \\
\hline Belírio & Computador, celular. & Causa câncer no pulmão. \\
\hline Cádmio & $\begin{array}{l}\text { Soldas, tabaco; baterias } \\
\text { e pilhas, computador, } \\
\text { monitores de tubo antigos. }\end{array}$ & $\begin{array}{l}\text { Câncer de pulmões e } \\
\text { próstata, lesão nos rins, } \\
\text { danos aos ossos, causa } \\
\text { envenenamento. }\end{array}$ \\
\hline Chumbo & $\begin{array}{l}\text { Fabricação e reciclagem de } \\
\text { baterias de automóveis; } \\
\text { indústria de tintas, pintura } \\
\text { em cerâmicas; soldagem. } \\
\text { Encontrado em celulares, } \\
\text { computadores, televisões. }\end{array}$ & $\begin{array}{c}\text { Saturnismo (cólicas } \\
\text { abdominais, tremores, } \\
\text { fraqueza muscular, lesão } \\
\text { renal e cerebral), causa } \\
\text { danos ao sistema nervoso e } \\
\text { sanguíneo. }\end{array}$ \\
\hline Cobalto & $\begin{array}{l}\text { Preparo de ferramentas de } \\
\text { corte e furadoras. }\end{array}$ & $\begin{array}{c}\text { Fibrose muscular } \\
\text { (endurecimento do pulmão) } \\
\text { que pode levar à morte. }\end{array}$ \\
\hline Cromo & $\begin{array}{c}\text { Indústria de corantes, } \\
\text { esmaltes, tintas, ligas com } \\
\text { aço e níquel; cromagem de } \\
\text { metais. }\end{array}$ & Asma(bronquite); câncer \\
\hline Mercúrio & $\begin{array}{l}\text { Moldes industriais; certas } \\
\text { indústrias de cloro-soda; } \\
\text { garimpo de ouro; lâmpadas } \\
\text { fluorescentes. É encontrado } \\
\text { em computadores, monitores } \\
\text { e televisores de tela plana. }\end{array}$ & $\begin{array}{c}\text { Intoxicação do sistema } \\
\text { nervoso central, causa danos } \\
\text { ao fígado. }\end{array}$ \\
\hline Níquel & $\begin{array}{l}\text { Baterias, aramados, fundição } \\
\text { e niquelagem de metais, } \\
\text { refinarias. }\end{array}$ & $\begin{array}{l}\text { Câncer de pulmão e seios } \\
\text { paranasais. }\end{array}$ \\
\hline $\begin{array}{l}\text { Retardantes de } \\
\text { Chamas(BRT) }\end{array}$ & $\begin{array}{c}\text { Equipamentos eletrônicos } \\
\text { utilizados para prevenir } \\
\text { incêndios. }\end{array}$ & $\begin{array}{l}\text { Causam desordem } \\
\text { hormonais, nervosas e } \\
\text { reprodutivas. }\end{array}$ \\
\hline
\end{tabular}


Analisando-se que as substâncias encontradas nos componentes que fazem parte dos equipamentos eletrônicos são muito perigosas, percebe-se que é essencial ter prudência ao tratar-se do assunto do lixo eletrônico. Torna-se fundamental a manipulação desse tipo de material de forma adequada.

\subsection{METAIS PRESENTES EM UM COMPUTADOR}

Os metais são materiais muito importantes para a sociedade e, por serem bons condutores de eletricidade e serem resistentes, são utilizados para a fabricação de muitos equipamentos eletroeletrônicos, de seus componentes. Além disso, são utilizados em muitos outros setores como o automobilístico, de construção civil, entre outros.

Os materiais metálicos:

[...] são substâncias inorgânicas que contêm um ou mais elementos metálicos e que podem também conter alguns elementos não-metálicos. 0 ferro, 0 cobre, o alumínio, o níquel e o titânio são exemplos de elementos metálicos. [...] Os metais são geralmente bons condutores térmicos e eléctricos. Muitos deles são relativamente resistentes e dúcteis à temperatura ambiente, e muitos mantêm uma boa resistência mecânica mesmo a temperaturas elevadas. (SMITH, 1996, p. 6).

No quadro 2 estão relacionados os metais que estão presentes no computador, sua localização nesse equipamento, sua quantidade e índice de reciclagem.

\begin{tabular}{|c|c|c|c|}
\hline Material & $\% \mathrm{~m} / \mathrm{m}$ & \%Reciclável, $\mathrm{m} / \mathrm{m}$ & $\begin{array}{c}\text { Localização/ } \\
\text { Finalidade }\end{array}$ \\
\hline Al (alumínio) & 14,1720 & 80 & Estrutura, conexões \\
\hline $\mathrm{Pb}$ (chumbo) & 6,2980 & 5 & $\begin{array}{c}\text { Circuitos integrados, } \\
\text { soldas, baterias }\end{array}$ \\
\hline Ge (Germânio) & 0,0010 & 0 & Semicondutor \\
\hline Ga (Gálio) & 0,0010 & 0 & Semicondutor \\
\hline $\mathrm{Fe}$ (Ferro) & 20,4710 & 80 & Estrutura, encaixes \\
\hline $\mathrm{Sn}$ (estanho) & 1,0070 & 70 & Circuito integrado \\
\hline $\mathrm{Cu}$ (cobre) & 6,9280 & 90 & Condutor elétrico \\
\hline $\mathrm{Ba}$ (bário) & 0,0310 & 0 & Válvula eletrônica \\
\hline $\mathrm{Ni}$ (níquel) & 0,8500 & 80 & Estrutura, encaixes \\
\hline $\mathrm{Zn}$ (zinco) & 2,2040 & 60 & Bateria \\
\hline $\mathrm{Ta}$ (tântalo) & 0,0150 & 0 & Condensador \\
\hline $\mathrm{In}$ (Índio) & 0,0010 & 60 & Transistor, retificador \\
\hline $\mathrm{V}$ (vanádio) & 0,0002 & 0 & $\begin{array}{c}\text { Emissor de fósforo } \\
\text { vermelho }\end{array}$ \\
\hline
\end{tabular}




\begin{tabular}{|c|c|c|c|}
\hline Be (berílio) & 0,0150 & 0 & $\begin{array}{l}\text { Condutor térmico, } \\
\text { conectores (liga Be- } \\
\text { Cu) }\end{array}$ \\
\hline $\mathrm{Au}$ (ouro) & 0,0016 & 98 & Conexão, condutor \\
\hline Ti (titânio) & 0,0150 & 0 & Pigmentos \\
\hline Co (cobalto) & 0,0150 & 85 & Estrutura \\
\hline $\begin{array}{c}\mathrm{Mn} \\
\text { (manganês) }\end{array}$ & 0,0310 & 0 & Estrutura, encaixes \\
\hline Ag (prata) & 0,0180 & 98 & Condutor \\
\hline $\mathrm{Cr}$ (cromo) & 0,0060 & 0 & $\begin{array}{c}\text { Decoração, proteção } \\
\text { contra corrosão }\end{array}$ \\
\hline Cd (cádmio) & 0,0090 & 0 & $\begin{array}{l}\text { Bateria, chip, } \\
\text { semicondutor, } \\
\text { estabilizadores }\end{array}$ \\
\hline Hg (mercúrio) & 0,0020 & 0 & $\begin{array}{l}\text { Baterias, ligamentos, } \\
\text { termostatos, sensores }\end{array}$ \\
\hline
\end{tabular}

Quadro 2: Elementos presentes em um computador Fonte: Adaptado de Cândido e Silva (2007)

\subsection{MATERIAIS QUE COMPÕEM O COMPUTADOR, NOTEBOOK E MONITORES CRT}

A tecnologia surgiu inicialmente como uma forma de solucionar inúmeros problemas do cotidiano das pessoas, automatizar várias tarefas dos indivíduos. Contudo o que se observou foi um processo totalmente contrário no qual, através de uma transformação silenciosa, produziram-se quantidades enormes de lixo relacionado às tecnologias. Entre esses eletrônicos estão os computadores, equipamentos que se destacam na indústria da informática, tendo uma demanda cada vez maior e, ao mesmo tempo, um índice de obsolescência também elevado. Os computadores em geral têm em sua composição inúmeros materiais. A maioria deles tem um potencial poluidor muito grande, fato que enfatiza a importância da correta destinação desses equipamentos.

Observa-se que nos computadores o material que predomina é o ferro, que compõe $68 \%$ desses equipamentos. Além disso, encontram-se placas, plásticos, fios e cabos, alumínio e inox. Já no notebook o material predominante é o plástico, que corresponde a $31 \%$ desses equipamentos. Também estão presentes os metais não-ferrosos, o vidro, o ferro, cabos e placas (ITAUTEC, 2003).

Nos monitores CRT observa-se que 59\% do equipamento é composto de cinescópio. O ferro, fios e cabos, placas, plásticos e alumínio também fazem parte da composição desses monitores (ITAUTEC, 2003).

Ao analisar-se a proporção em quilogramas dos materiais que compõem os microcomputadores se verifica que o ferro é o que está em maior quantidade, estando 
presente em 7,3 kg do computador. Os outros materiais como as placas eletrônicas, plástico, alumínio, fios e cabos, estão presentes na proporção de 1,6 kg, 0,7 kg, 0,6 kg e $0,5 \mathrm{~kg}$ (ITAUTEC, 2003).

\subsection{LIXO ELETRÔNICO E A LEGISLAÇÃO}

Precisa-se ainda melhorar muito para que se possa conseguir uma redução significativa nos impactos ambientais provocados pela destinação indevida dos materiais provenientes do lixo eletrônico. No Brasil ainda não se tem uma lei específica para impor uma obrigação ao fabricante e até mesmo ao consumidor de dar um destino correto a esses detritos. Está em andamento na Câmara dos Deputados um projeto para a aprovação da Lei Nacional de Resíduos Sólidos que regulamenta a correta destinação de alguns produtos. No entanto, tal projeto de lei exclui a responsabilidade dos fabricantes em relação à destinação de produtos eletroeletrônicos.

Em relação à lei vigente, nota-se que a única responsabilidade que se tem é associada às pilhas e baterias que, conforme a resolução número 257 do Conselho Nacional do Meio Ambiente (CONAMA), devem ser recolhidas pelos seus fabricantes e encaminhadas para processos que dêem um fim correto a esses materiais. Nessa resolução, o 3 o artigo impõe a obrigatoriedade dos estabelecimentos que comercializam pilhas e baterias e as redes de assistência técnica autorizadas pelos fabricantes e importadores desses produtos a aceitar a devolução das unidades usadas (BRASIL, 1999).

Analisando-se a legislação de alguns estados brasileiros observa-se que Minas Gerais, Rio Grande do Sul, Ceará, Piauí, Rio de Janeiro, Paraná e São Paulo, não mencionam os resíduos eletrônicos na Política Estadual de Resíduos Sólidos. No estado de São Paulo há uma lei específica para o lixo eletrônico que está em vigor desde 2008 e obriga os fabricantes, importadores e comerciantes de equipamentos eletrônicos a fazer a logística reversa, reciclagem e deposição adequada desses resíduos. Já em Pernambuco, há um Decreto de Resíduos Eletrônicos, em vigor desde 2002, que classifica os eletrônicos como um lixo especial. Também nesse estado, a Política Estadual de Resíduos Sólidos, obriga a indústria de eletrônicos a apresentar um plano de gerenciamento de resíduos sólidos da produção, mas não dos produtos comercializados (ANDUEZA, 2009a).

Observa-se que no mundo existem algumas leis que regulamentam a destinação dos resíduos eletrônicos. A União Européia tem a Diretiva Restriction on the use of

Hazardous Substances (ROHS) e Waste Electrical and Electronic Equipment (WEE) que regem alguns aspectos relacionados aos equipamentos eletrônicos desse bloco. A primeira diretiva que está em vigor desde 2003, restringe seis substâncias tóxicas (chumbo, mercúrio, cádmio, cromo hexavalente e polibromatos bifenilos polibromados (PBB) e éteres de difenilo polibromado (PBDE) nesses materiais. De acordo com essa lei os produtores têm a responsabilidade de diminuir o uso dessas substâncias. A segunda diretiva, que está em vigor desde 2002, além de substituir as substâncias 
tóxicas tem por objetivo, aumentar a taxa de reciclagem de equipamentos eletrônicos e proibir o depósito inadequado desses detritos. Segundo essa lei é de responsabilidade dos Estados estabelecerem sistemas de coleta e dos produtores de praticar a logística reversa e reciclagem. $O$ consumidor é proibido de jogar esses resíduos no lixo comum (ANDUEZA, 2009b).

A China também possui uma lei para o lixo eletrônico. Essa lei está em vigor desde 2006 e segue os mesmos padrões da diretiva ROHS da União Européia. Já nos Estados Unidos existem duas leis: Decreto de Reciclagem de Eletrônicos (baseado na WEE e ROHS) e a Electronic Equipment Collection. Esta foi sancionada em 2008 e define que os produtores têm que submeter o plano de manejo do lixo à prefeitura, além de ser proibido descartar eletrônico no lixo comum ou aterro sanitário. Aquela está em vigor desde 2003 e responsabiliza o consumidor de enviar os materiais para reciclagem, os produtores de implantar redes de coleta e o Estado de garantir que a reciclagem aconteça (ANDUEZA, 2009b).

No Japão existe a lei Home Appliance Recycling Law que vigora desde 1998 e tem como princípio a substituição de substâncias tóxicas, aumento da reciclabilidade e proibição do depósito inadequado. Por essa lei o consumidor fica obrigado a pagar uma taxa para descartar seus produtos eletroeletrônicos, o Estado é responsável pelo sistema de coleta e logística reversa e o produtor deve reciclar e neutralizar os componentes tóxicos presentes nesses equipamentos (ANDUEZA, 2009b).

No âmbito mundial existe a Convenção de Basiléia, que vigora desde 1989 e regulamenta o movimento internacional de resíduos tóxicos entre os países signatários. Conforme essa convenção, o Estado fica responsabilizado de regularizar e fiscalizar todo o fluxo de importação e exportação de resíduos tóxicos. O lixo eletrônico é dividido em duas categorias: altamente tóxico (baterias e monitores de TV) e moderadamente tóxico (qualquer resíduo de equipamento eletroeletrônico que não seja bateria e monitor de TV) (ANDUEZA, 2009b).

\section{COMO SURGIU A IDÉIA DO PROJETO “E-WASTE - LIXO ELETRÔNICO”}

O projeto "E-waste - Lixo Eletrônico" partiu da preocupação demonstrada pelo coordenador do Curso Técnico em Informática do SENAI/SC em São Miguel do Oeste, pelo correto destino do lixo eletrônico encontrado na unidade.

Numa visita realizada pelos alunos do ensino médio articulado com educação profissional juntamente com alguns colaboradores da unidade a uma empresa que trabalha com aterro, na cidade de Chapecó/SC, observou-se o impacto que esse tipo de material tem no meio ambiente. Verificou-se que, caso fosse mandado para o aterro o lixo eletrônico demoraria bastante tempo para se decompor e poderia poluir a natureza. Sendo assim, percebeu-se que o melhor destino é a reciclagem. 
Como na região extremo oeste catarinense não existe nenhuma empresa que recicla lixo eletrônico e como a quantidade desse tipo de resíduo no SENAI/SC em São Miguel do Oeste é considerável, observou-se a necessidade de dar um destino adequado a esses materiais.

Além disso, verificou-se que pouco se falava, na comunidade regional, sobre a reciclagem de resíduos tecnológicos e sobre a importância de tal ação. Sendo assim, julgou-se importante realizar uma campanha no município de São Miguel do Oeste e demais municípios da região, para a coleta desse tipo de resíduo e promover um trabalho de conscientização com a comunidade.

\subsection{O LIXO ELETRÔNICO NO SENAI/SC EM SÃO MIGUEL DO OESTE}

Na unidade do SENAI/SC em São Miguel do Oeste a maior parte do lixo eletrônico é produzida pela área de informática. Outras áreas como elétrica, mecânica, segurança no trabalho e alimentos, também contribuem, de forma menos expressiva para o acúmulo desse tipo de material.

Considerando que a região oeste catarinense carece de empresas que trabalhem com a reciclagem de lixo eletrônico, fato que dificulta a destinação desses resíduos, o número de equipamentos e componentes eletrônicos obsoletos ou estragados acabou crescendo consideravelmente na instituição. Assim, materiais como mouses, teclados, HD's, driver's, fontes de computadores, impressoras, memórias, processadores, transformadores, estruturas de gabinetes de computadores, placas de circuito eletrônico, CD's, monitores de computador, placas diversas e fios, acumularam-se e tornaram-se um problema para a unidade. As fotos abaixo apresentam os resíduos tecnológicos:

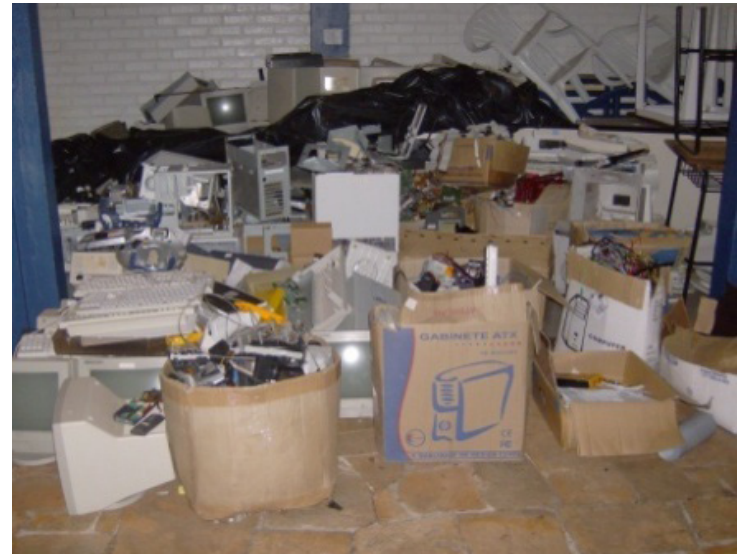

Foto 1: Lixo eletrônico do SENAI/SC em São Miguel do Oeste

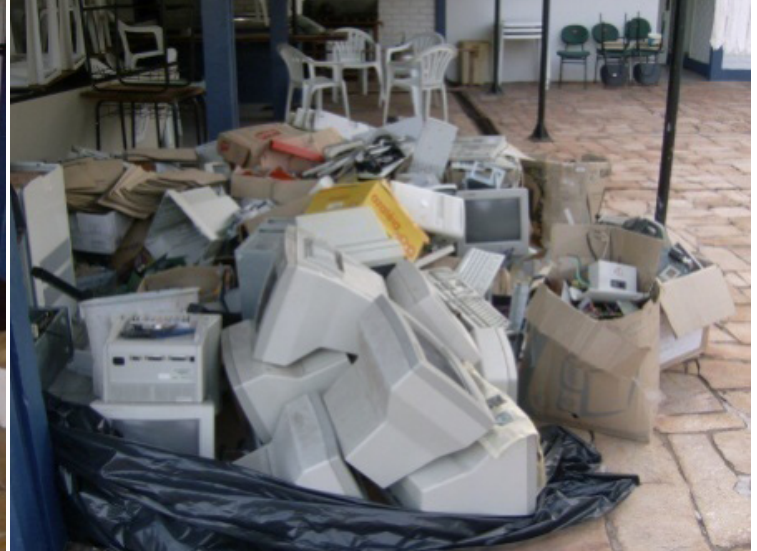

Foto 2: Parte do lixo eletrônico do SENAI/SC em São Miguel do Oeste 


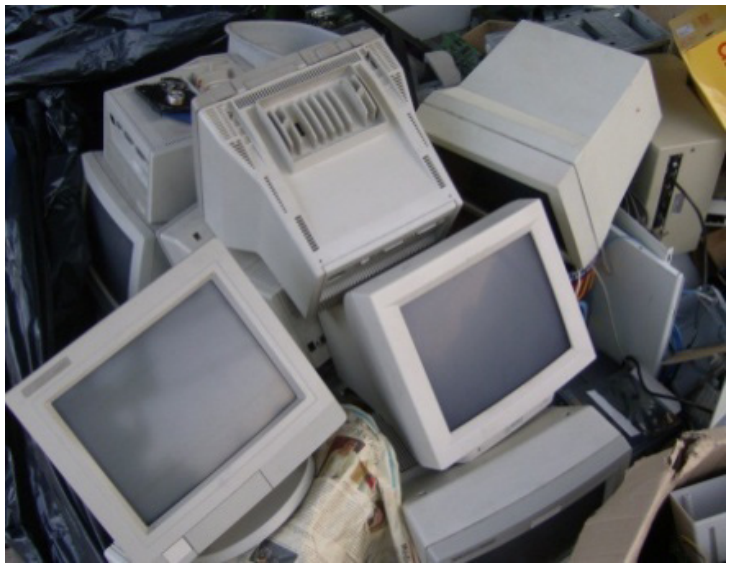

Foto 3: Monitores Arrecadados

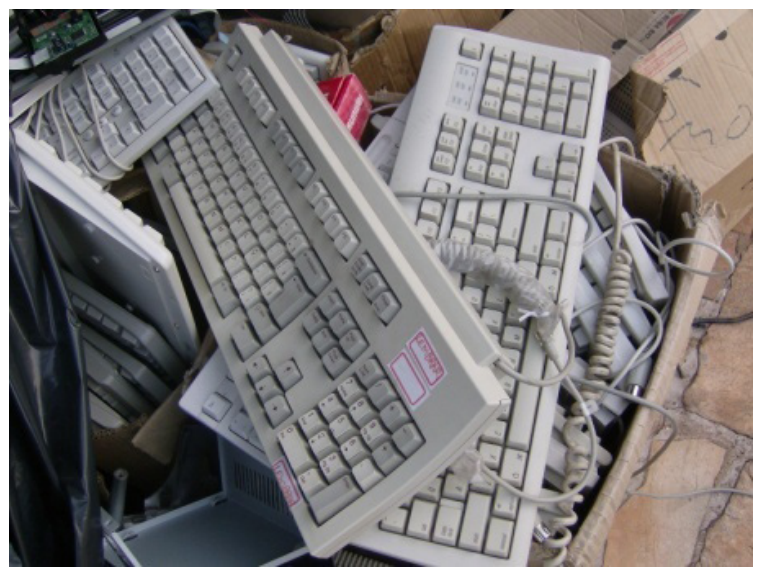

Foto 4: Teclados Arrecadados

\subsection{APLICAÇÃO DO PROJETO “E-WASTE - LIXO ELETRÔNICO”}

Através do projeto "E-waste - Lixo Eletrônico" foi realizada uma campanha para a coleta e destinação desse material na cidade de São Miguel do Oeste/SC. O evento aconteceu de 03 a 10 de outubro de 2009 e, na oportunidade, o SENAI serviu como ponto de coleta assim como algumas empresas de informática do município.

O material recebido passou pelos seguintes processos:

a) armazenamento do material no ecoponto da AMEOSC;

b) desmontagem;

c) separação do lixo de acordo com o tipo de material (plástico ABS, metal, fios, placas, baterias, pilhas);

d) separação do lixo que podia ser reaproveitado na unidade como material didático ou, no caso dos metais, como matéria-prima para as atividades relacionadas ao núcleo de Eletromecânica da unidade;

e) envio de cada tipo de lixo para seu respectivo destino.

\subsection{O QUE FOI ARRECADADO NA CAMPANHA}

A campanha do lixo eletrônico arrecadou os seguintes materiais:
a) computadores e servidores completos;
b) processadores;
c) mouse; 
d) estabilizador/Nobreak/Swiffs;

e) CPU's;

f) impressoras;

g) fontes adaptadoras;

h) memória;

i) placas de circuito eletrônico;

j) aparelho de DVD/Vídeo;

k) notebook;

I) teclado;

m) caixas de som;

n) hd's;

o) fax;

p) fonte de micros;

q) transformador;

r) cd-rom;

s) centrais telefônicas;

t) drivers diversos;

u) baterias de celulares;

v) pilhas.

\subsection{QUEM FEZ PARTE DA CAMPANHA}

O projeto mobilizou os alunos e os colaboradores do SENAI/SC em São Miguel do Oeste, as autoridades, o comércio e a comunidade em geral do município. Cada qual teve um papel muito importante na campanha.

Alunos e colaboradores da unidade contribuíram no processo de separação do lixo eletrônico interno e do recebido pela campanha bem como para a definição de métodos para que tal atividade acontecesse. Alguns colaboradores foram responsabilizados pela divulgação do projeto e pela destinação dos materiais separados. 
O comércio, representado nesse projeto por algumas empresas de informática do município e pelo Supermercado Treviso, colaborou com a coleta dos equipamentos eletrônicos obsoletos bem como seu transporte até o SENAI/SC em São Miguel do Oeste e o ecoponto da AMEOSC para o devido destino. O Supermercado Treviso realizou o trabalho de destinação das pilhas.

A AMEOSC, representando as autoridades, contribuiu com a campanha, disponibilizando um local para o acondicionamento do lixo coletado e responsabilizando-se pelo transporte desse material para empresas que dão o destino final. Já a comunidade colaborou enviando o lixo eletrônico que possuía para os pontos de coletas definidos na campanha.

\subsection{PARCERIAS DO PROJETO, DESTINO E TRATAMENTO DOS MATERIAIS}

Para a realização da campanha foram firmadas parcerias com as seguintes instituições e empresas: Associação dos Municípios do Extremo Oeste de Santa Catarina - AMEOSC, empresa BL Fibras, Supermercado Treviso.

A AMEOSC viabilizou o transporte do lixo eletrônico coletado para a cidade de Joaçaba/ $\mathrm{SC}$ onde o mesmo foi entregue à empresa Alpha Lixo Digital que atua no ramo de coleta e destinação ambiental de resíduos tecnológicos. A AMEOSC também disponibilizou seu eco ponto para que o material coletado fosse devidamente acondicionado até ser enviado a Joaçaba/SC. A empresa BL Fibras, de Anchieta/ SC, fez o trabalho de moagem do plástico $A B S e d o s$ equipamentos eletrônicos para que posteriormente o mesmo fosse enviado para a Associação dos Coletores de Material Reciclável de São Miguel do Oeste SC (ACOMAR), sendo que os vidros e os metais também foram enviados a essa instituição.

O Supermercado Treviso situado no município de São Miguel do Oeste - SC recebeu as pilhas coletadas através da campanha e as entregou para os vendedores desses materiais que repassaram os mesmos para os respectivos fabricantes que efetuaram a reciclagem das pilhas conforme seus programas de reciclagem.

Os resíduos tecnológicos enviados a empresa Alpha Lixo Digital foram separados, sendo que cada tipo de material foi enviado a diferentes empresas que trabalham com reciclagem. Alguns materiais como placas foram destinados para uma empresa exportadora que as enviou para a Europa para que ocorresse o processo de reciclagem. Tal procedimento foi adotado pelo fato de no Brasil não haver empresas especializadas em recuperar tais materiais.

Os componentes tóxicos presentes no lixo eletrônico recebem tratamento para que assim não agridam o meio ambiente, sendo que todos são transformados em matériaprima, recebendo tratamento dentro ou fora do país, dependendo do caso. Em relação às placas eletrônicas, por exemplo, metais pesados como o mercúrio são retirados dos componentes e reciclados ou reaproveitados para a fabricação de outros materiais. A reciclagem desses metais pesados só é possível fora do país devido ao fato de que o Brasil não possui tecnologia suficiente para realizar tal processo. 


\subsection{RESULTADOS OBTIDOS NA CAMPANHA EM SÃO MIGUEL DO OESTE/ SC}

A campanha realizada em São Miguel do Oeste teve boa aceitação tanto pela população quanto pelas empresas. Por meio dos pontos de coleta estabelecidos conseguiu-se arrecadar 15 toneladas de lixo eletrônico. Nas fotos abaixo pode-se observar o material recolhido:

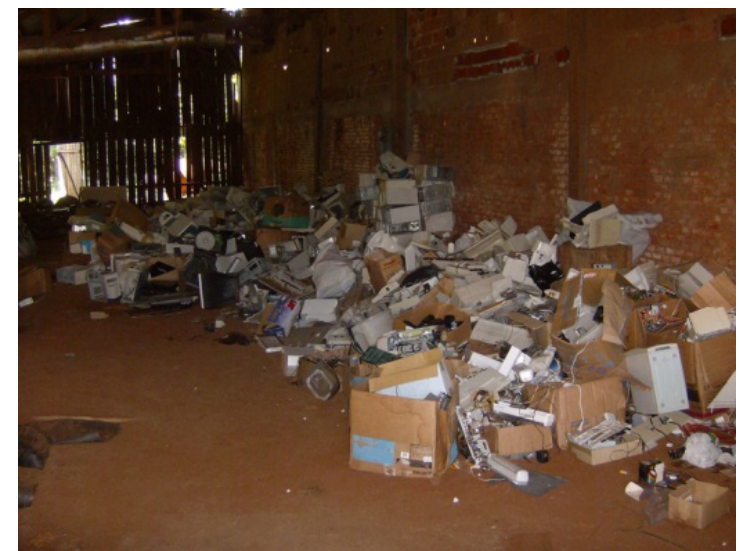

Foto 5: Lixo eletrônico arrecadado

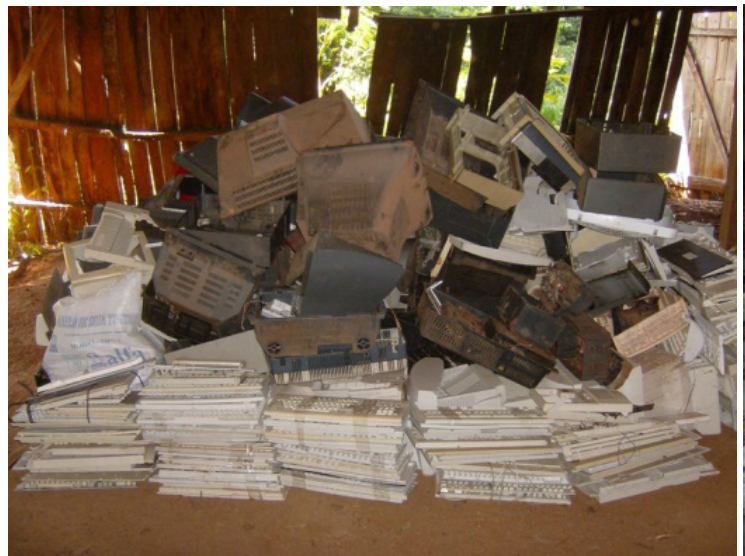

Foto 7: Estruturas metálicas

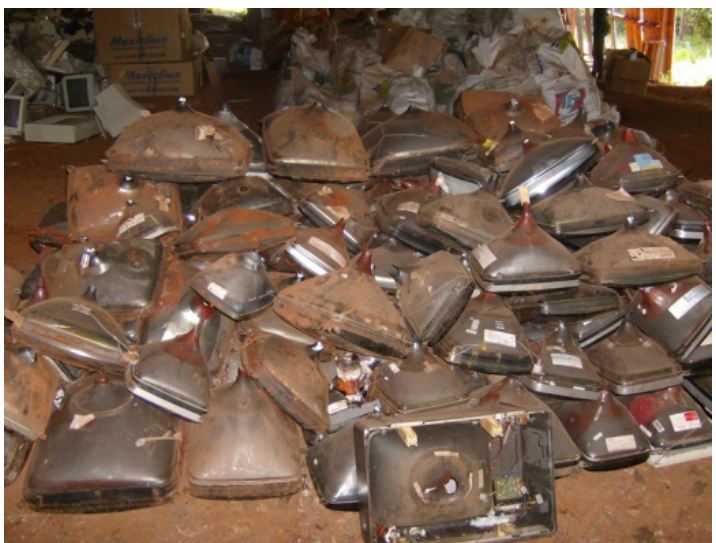

Foto 9: Tubos de imagem

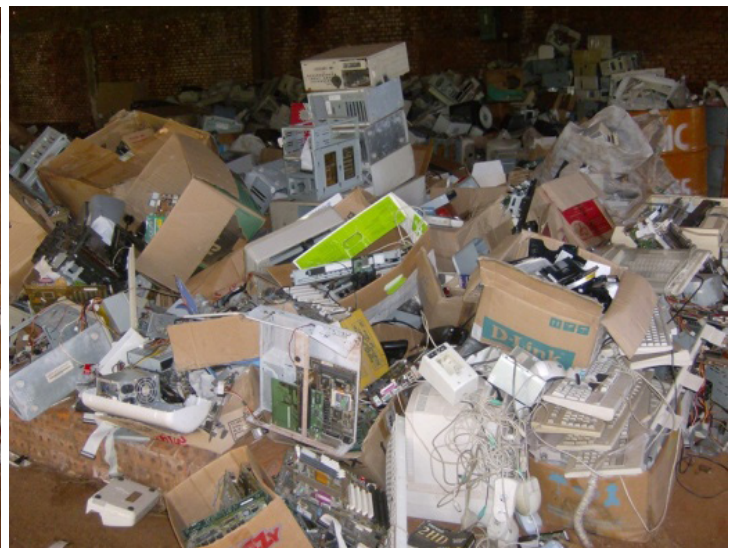

Foto 6: Parte do lixo eletrônico arrecadado

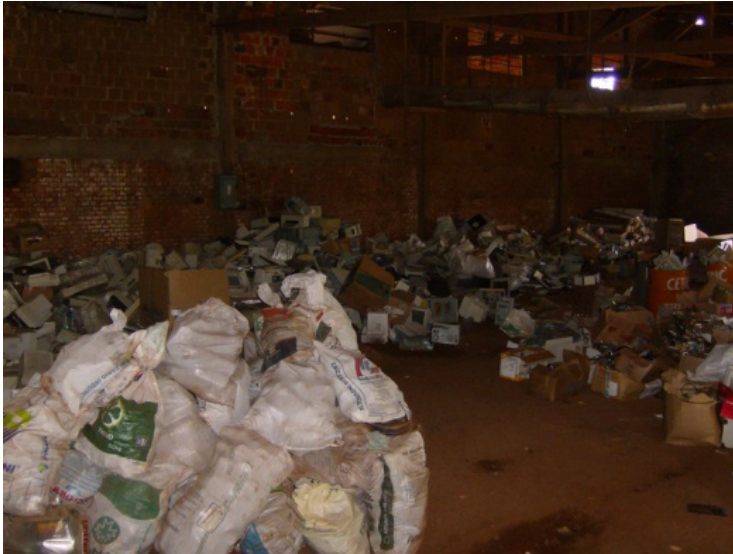

Foto 8: Lixo Eletrônico arrecadado

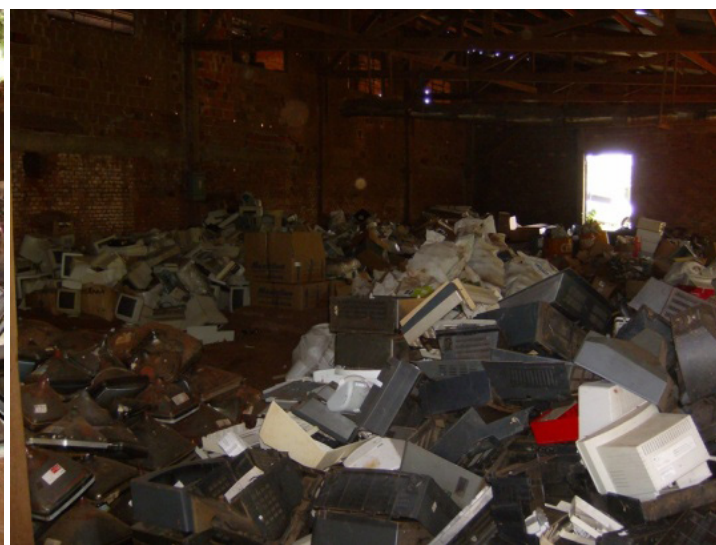

Foto 10: Lixo Eletrônico arrecadado 


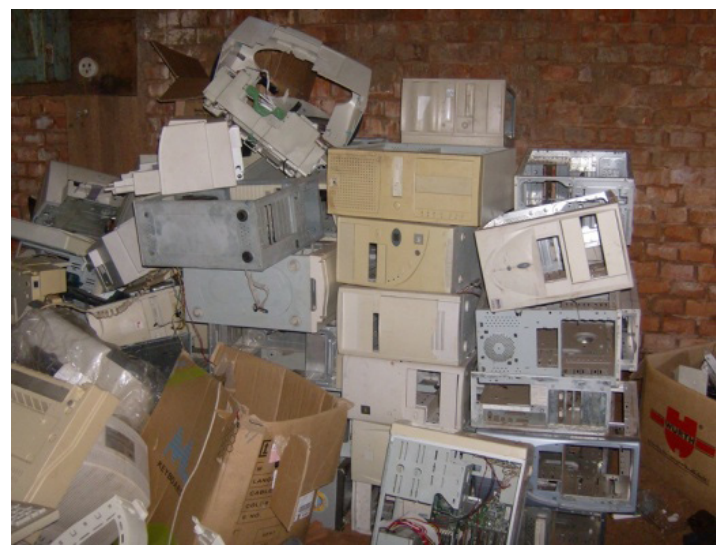

Foto 11: gabinetes

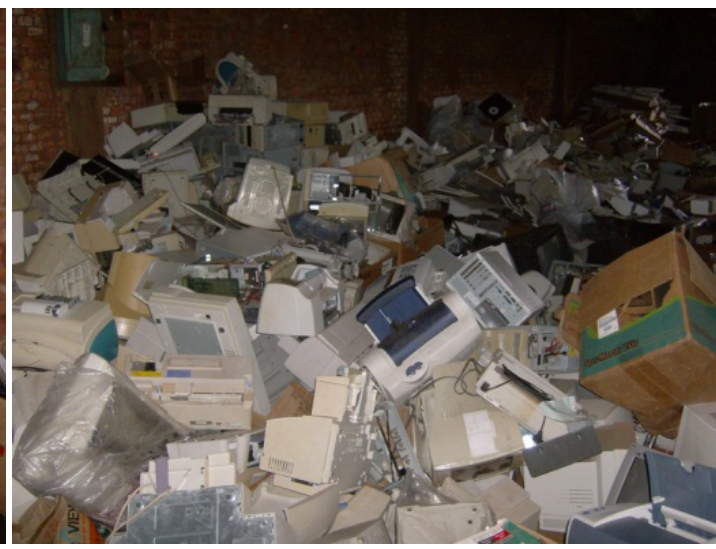

Foto 12: Equipamentos eletrônicos

A iniciativa foi de grande importância para a cidade de São Miguel do Oeste, pois oportunizou a correta destinação dos materiais eletrônicos obsoletos e proporcionou a sociedade um melhor entendimento no que diz respeito a necessidade de se reciclar esses materiais ou de reutilizá-los. Além disso, contribuiu para despertar em outros municípios da região o interesse em tomar iniciativas para o combate da poluição causada pelos resíduos eletrônicos.

\subsection{RELEVÂNCIA DO PROJETO}

O projeto "E - waste - Lixo Eletrônico" está engajado na busca de alternativas para, dentro da instituição SENAI e do município de São Miguel do Oeste, amenizar os impactos ambientais provocados pelo lixo eletrônico bem como reduzir custos através da reciclagem. Outro enfoque é promover a reutilização desses equipamentos na unidade para que se consiga diminuir o índice de obsolescência entre esses materiais.

Um fator relevante é que com o projeto a instituição SENAI/SC em São Miguel do Oeste está difundindo uma cultura ecologicamente correta entre seus alunos e colaboradores. Como o SENAI/SC utiliza o método de ensino por competências através da avaliação do conhecimento, da habilidade e da atitude do aluno, pode-se verificar se de fato os estudantes se mostram ativos no que diz respeito à solução de problemas relacionados ao meio ambiente. Assim, o educando que realmente procura desenvolver atitudes do aluno reconhece a importância da preservação do meio ambiente e aqueles que não dão o devido valor ao problema puderam, através do projeto, perceber a necessidade da adoção de medidas que visam melhorar o meio em que se vive.

Assim, podem ser desenvolvidas algumas habilidades nos alunos como a formação de uma consciência ecológica e prática de ações sustentáveis.

A instituição também tem um papel fundamental alertando a população sobre a importância do destino correto do lixo eletrônico produzido pelos indivíduos e empresas. 
Considerando-se o lixo eletrônico como um problema mundial, é fundamental que o SENAI, como uma organização seriamente preocupada com o desempenho ambiental e comprometida com questões sociais relacionadas à preservação do meio ambiente, tome iniciativas que venham combater a poluição causada pelo descarte inconseqüente de material eletrônico e, assim, estabelecendo um modelo que possa ser seguido por outras entidades no sentido de proteger o meio ambiente das montanhas de produtos eletrônicos que são rejeitados.

\section{EXPANSÃO DO PROJETO}

A região do extremo oeste catarinense carece de iniciativas em relação ao lixo eletrônico. Há falta de empresas que realizem trabalho de reciclagem desses detritos e, além disso, muitas cidades não se preocupam com esse tipo de problema.

Nesse sentido, o SENAI/SC em São Miguel do Oeste por meio do projeto "E-waste - Lixo eletrônico" irá realizar campanhas para recolhimento do lixo eletrônico em todos os municípios que compõem a AMEOSC: Anchieta, Bandeirante, Barra Bonita, Belmonte, Descanso, Dionísio Cerqueira, Guaraciaba, Guarujá do Sul, Iporã do Oeste, Itapiranga, Mondaí, Palma Sola, Paraíso, Princesa, Santa Helena, São João do Oeste, São José do Cedro, São Miguel do Oeste e Tunápolis, buscando ajudar a diminuir os impactos causados pela indevida destinação desse lixo em toda a região.

A expansão do projeto para os demais municípios da região acontecerá por meio do auxílio da AMEOSC que reunirá as autoridades dos municípios com o objetivo de firmar acordo para colocar o projeto em prática. Cada cidade organizará todo o processo de recolhimento dos resíduos e transporte para o eco ponto da AMEOSC.

Para as próximas campanhas realizadas pelo projeto o lixo eletrônico será enviado à empresa Eco Centro Sul de Lages-SC, sendo que as empresas que fizerem a destinação desses resíduos receberão certificação.

Além disso, o SENAI/SC em São Miguel do Oeste tem o propósito de estender o projeto para todas as unidades do SENAI/SC, para que as mesmas possam atuar na diminuição dos impactos ambientais causados pelo lixo eletrônico de forma efetiva em suas realidades regionais.

NoSENAI/SC a expansão acontecerá por meio de exposição para as demais unidades sobre o propósito do projeto e reuniões para que se definam meios de organizar campanhas voltadas para a realidade em que cada unidade está inserida. A responsabilidade pela continuidade do projeto será de cada unidade. 


\section{CONCLUSÕES}

Com a aplicação do projeto "E-waste - lixo eletrônico", pode-se perceber a redução significativa na quantidade de lixo eletrônico encontrado no SENAI/SC em São Miguel do Oeste bem como dar a destinação correta para o lixo eletrônico produzido na cidade de São Miguel do Oeste e dos demais municípios integrantes da AMEOSC. Com a campanha realizada pelo projeto recolheram-se quinze toneladas de resíduos eletrônicos.

É importante ressaltar que o SENAI recebeu importantes colaborações para a realização do projeto como a ajuda da AMEOSC no transporte e acondicionamento dos materiais e as parcerias de algumas empresas de São Miguel do Oeste para a coleta de equipamentos eletrônicos.

Além disso, a comunidade teve a oportunidade de conhecer melhor como descartar seus equipamentos eletrônicos obsoletos e foi alertada sobre a importância de se destinar adequadamente esses resíduos. Assim, muito mais que recolher o lixo tecnológico, o projeto teve grande importância em relação à conscientização das pessoas sobre a problemática do lixo eletrônico.

Vale destacar que instituições ou indivíduos que manifestarem interesse em realizar projetos similares em suas comunidades devem buscar primeiramente conhecer melhor sobre a composição do lixo eletrônico, sua forma de acondicionamento e quais empresas que realizam o trabalho de reciclagem ou de gerenciamento desses resíduos para que os mesmos possam receber destinos corretos. É imperativo destacar que se deve buscar trabalhar com empresas que tenham certificação dos órgãos fiscalizadores competentes.

Além disso, para que os projetos tenham uma abrangência maior é importante que se estabeleçam parcerias com órgãos governamentais ou instituições privadas. Assim, as mesmas poderão dar suporte em questões importantes no projeto como o transporte e o acondicionamento dos materiais.

É imprescindível que se tome iniciativas em relação ao aumento do índice de obsolescência dos eletrônicos e a conseqüente geração de passivos ambientais que comprometem a preservação da natureza. Medidas como essas tomadas pelo SENAI devem ser postas em prática pela sociedade para que se consiga mudar o caminho que a humanidade está trilhando em relação à preservação do meio ambiente. 


\section{REFERÊNCIAS}

ANDUEZA, Felipe. Legislação brasileira comparada de lixo eletrônico e resíduos sólidos. 2009a. Disponível em: < http://www.lixoeletronico.org/blog/legislacaobrasileira-comparada-de-lixo-eletronico-e-residuos-solidos> Acesso em: 25 set.2009.

ANDUEZA, Felipe. Legislação internacional comparada do lixo eletrônico. 2009b. Disponível em: < http://www.lixoeletronico.org/blog/legislacao-internacionalcomparada-de-lixo-eletronico> Acesso em: 25 set. 2009.

BRASIL. Ministério do Meio Ambiente. Conselho Nacional do Meio Ambiente. Resolução № 257, de 30 de junho de 1999. Disponível em: <http://www.mma.gov.br/ port/conama/res/res99/res25799.html> Acesso em: 15 set. 2009.

CÂNDIDO, Carlos Eduardo de Farias; SILVA, Wagner Campos da. Educação ambiental: o lixo eletrônico. 2007. 50 f. Trabalho de conclusão de curso Química com atribuição tecnológica - Universidade Federal do Rio de Janeiro, Rio de Janeiro, 2007. Disponível em: <http://iq.ufrj.br/ recicla_iq/monografia_kadu.pdf>. Acesso em: 18 set.2009.

CUT. Metais Pesados. [20--? ]. Disponível em: <http://www.fiec.org.br/iel/ bolsaderesiduos/Artigos/Artigo_Metais\%20Pesados.pdf>. Acesso em: 15 set.2009.

FONSECA, Felipe. Lixo eletrônico. In: SPYER, Juliano (Org.). Para entender a Internet: noções, práticas e desafio da comunicação em rede. 2009. Disponível em: <http:// www.next.icict.fiocruz.br/arquivos/Para+entender+a+Internet.pdf $>$. Acesso em: 20 set. 2009.

FUNDAÇÃO NACIONAL DA QUALIDADE. Cadernos de excelência: sociedade. São Paulo, 2008. Disponível em: < https://www.fnq.org.br/pdf/CadernosExcelencia2008_04_ sociedade.pdf>. Acesso em: 18 abr. 2010.

ITAUTEC. O computador por dentro. [2003].Disponível em: <http://www.itautec. com.br/iPortal/pt-BR/32eae81e-5275-4030-aee3-12fecac020c1.htm>. Acesso em: 16 set.2009. 
MOREIRA, Daniela. Lixo eletrônico tem substâncias perigosas para a saúde

humana. p.1-.2. 2007. Disponível em: <http://idgnow.uol.com.br/computacao_ pessoal/2007/04/26/idgnoticia.2007-04-25.3237126805/>. Acesso em: 07 maio2009.

SERVIÇO NACIONAL DE APRENDIZAGEM INDUSTRIAL. Departamento Nacional. PSQA Programa SENAI de qualidade ambiental. Brasília, 1992.

SERVIÇO NACIONAL DE APRENDIZAGEM INDUSTRIAL. Departamento Regional de Santa Catarina. Balanço Social. 2010a. Disponível em: < http://www.sc.senai.br/ siteinstitucional/docs/balanco_social.pdf>. Acesso em: 23 mai. 2010.

SERVIÇO NACIONAL DE APRENDIZAGEM INDUSTRIAL. Departamento Regional de Santa Catarina. Relatório de gestão 2009. Florianópolis, 2010b. Disponível em: < http:// www.sc.senai.br/siteinstitucional/docs/relatorio-de-gestao-2009.pdf>. Acesso em: 18 abr.2010.

SMITH, William Fortune. Princípios de ciência e engenharia de materiais. 3. ed. Lisboa: McGraw-Hill, 1996.

Originais recebidos em: 30/09/2009

Texto aprovado em: 06/05/2010 


\section{SOBRE OS AUTORES}
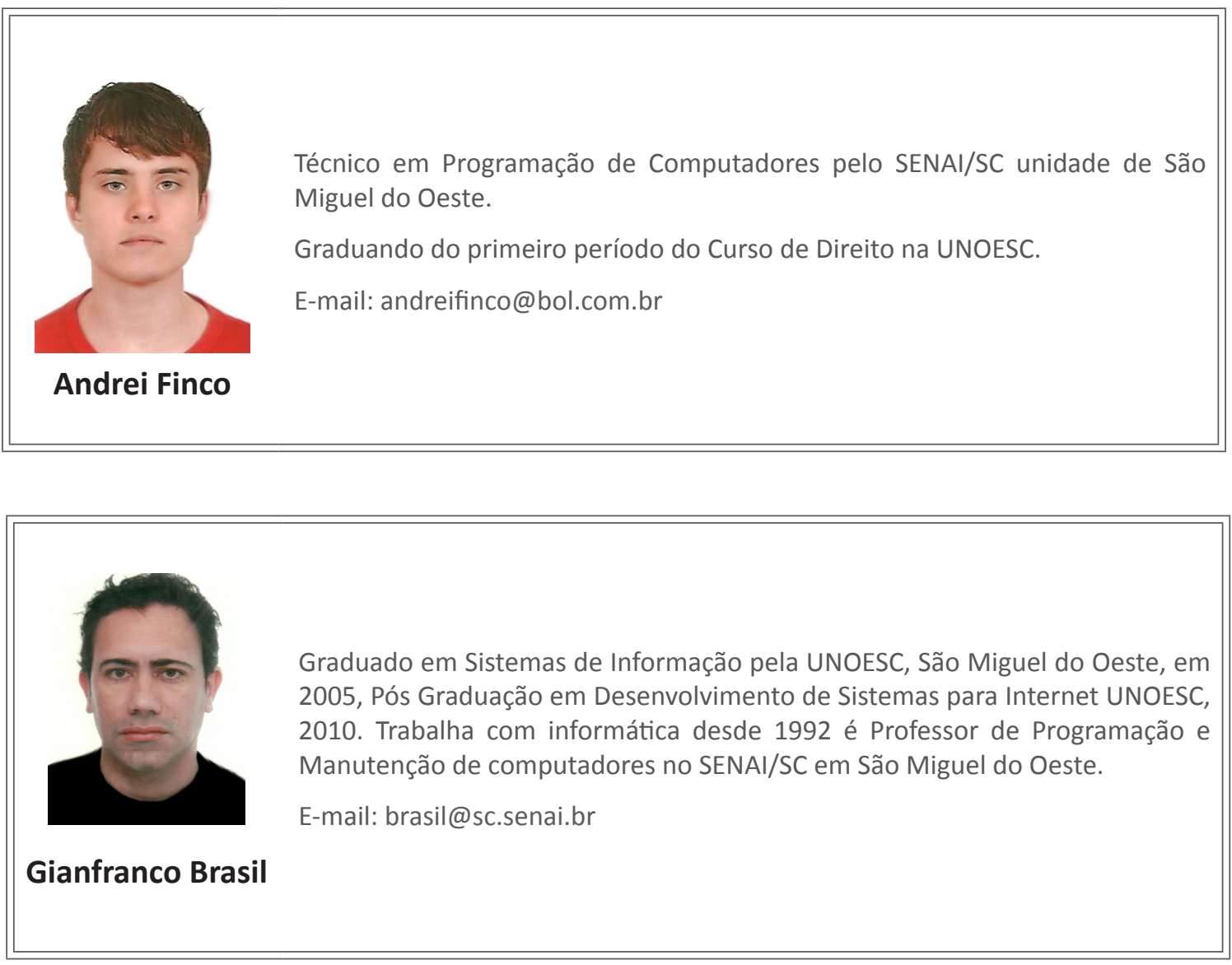